\title{
A Comparison of Anterolateral and Posterolateral Approaches in Primary Total Hip Arthroplasty
}

\section{Faruk BUĞLAK ${ }^{1}$, Mehmet A. E. AKSEKILi ${ }^{2}$, Kasım KILIÇARSLAN ${ }^{3}$, Bahar ANAFOROĞLU ${ }^{4}$, İzzet KORKMAZ}

\footnotetext{
${ }^{1}$ Department of Orthopedics, Malatya State Hospital, Malatya, Turkey.

${ }^{2}$ Department of Orthopedics, School of Medicine, Yıldırım Beyazıt University, Ankara, Turkey.

${ }^{3}$ Department of Orthopedics and Traumatology, Atatürk Training and Research Hospital, Ankara, Turkey.

${ }^{4}$ Department of Physical Therapy and Rehabilitation, Faculty of Health Sciences, Yıldırım Beyazıt University, Ankara, Turkey.

${ }^{5}$ Department of Orthopedics, Gölbaşı Hasvak State Hospital, Ankara, Turkey.
}

\section{ABSTRACT}

The aim of this study was to compare the short-term clinical and radiological results of anterolateral and posterolateral approaches in total hip arthroplasty.

The study included patients who were operated on for hip osteoarthritis. The patients were allocated to one of two groups for applying uncemented total hip prosthesis with the anterolateral or posterolateral approach. They were operated on by one surgical team composed of two senior surgeons. They were clinically evaluated using the Harris Hip Score and radiologically using direct radiographs. Various parameters were recorded in both the groups, including amount of blood loss, surgical time, and duration of hospitalization.

A total of 70 patients were followed up for a mean duration of 18 months (range 6-36 months), 34 in the anterolateral group and 36 in the posterolateral group. No statistically significant differences were observed between the anterolateral and posterolateral approaches for a total hip prosthesis in terms of the clinical and radiological results.

The most successful results can be obtained using the technique that the surgeon performs better according to his experience of total hip arthroplasty.

Key words: Anterolateral surgical approach, posterolateral surgical approach, total hip arthroplasty

\section{INTRODUCTION}

Total hip arthroplasty (THA) is one of the most successful orthopedic surgical procedures in terms of eliminating hip pain for the patient, increasing mobility, and improving the quality of life (1). However, in some THA patients, functions cannot be improved to a sufficient degree when pain is not completely eradicated. Probable reasons for this include instability, insufficient adjustment of soft tissue balance, or surgical trauma (2). The complications of THA can be minimized using the correct surgical approach.

Several approaches have been defined for applying THA (3). The most commonly used of these are the anterolateral (modified Watson-Jones) and the posterior (Southern, Moore, Gibson, or posterolateral) approaches $(4,5)$. The anterolateral approach was first defined by Sprengel and Bardenhauer, and then later modified by Watson-Jones (6). In this approach, entry is made from the gluteus medius cleavage and the tensor fascia lata stimulated by the superior gluteal nerve (7). Trochanteric osteotomy or separation of a section from the adhesion point of the gluteus medius or minimus to the trochanter is necessary for sufficient acetabulum exposure $(7,8)$. In the posterior approach, the external rotator muscles of the hip are separated from the capsule after cutting from the adhesion point without touching the gluteus medius and minimus tissue by separating the split gluteus maximus muscle (9).

As different approaches have advantages and disadvantages, the debate is still ongoing as to which approach is superior to the others. Despite insufficient information on the long-term results of different approaches, some studies have reported on short-term results such as blood loss (10), perioperative pain (11), duration of hospitalization (12), and cosmetic results (12). 
Moreover, some approaches have been developed in the last 10 years to shorten the length of the incision. These approaches include the posterolateral technique (13); the double-incision technique used with the posterior cut of the modified Smith-Peterson approach (14); mini-posterior, mini-anterolateral technique (15); and modified anterolateral Watson-Jones technique (16). Studies have shown that bone stock, soft tissue innervation, and protection of the blood supply are much more important than the length of the incision (17).

The aim of this prospective, randomized, single-center study was to compare the short-term clinical and radiological results of the anterolateral and posterolateral approaches in THA.

\section{MATERIALS AND METHODS}

The approval for the study was granted by the local ethics committee. The study included patients who were operated on for hip osteoarthritis at a single center. They were allocated to one of two groups for applying uncemented total hip prosthesis with the anterolateral or posterolateral approach. They were operated on by one surgical team composed of two senior surgeons. Surgeon A operated on the anterolateral group, and surgeon B operated on the posterolateral group. Patients charts were reviewed, and data on complications, demographics, surgical time, intraoperative blood loss, length of incision, and length of stay were collected. Informed consent was obtained from all the participants. The study included patients who underwent primary uncemented prosthesis.

Standard preoperative and postoperative treatment protocols were applied to all patients. An accelerated rehabilitation program and postoperative standard range-of-motion exercises were applied to both the groups.

In the anterolateral approach, an incision of approximately $15 \mathrm{~cm}$ was made centered on the trochanter major. After exploration, the fascia lata was opened from the posterior of the tensor fascia lata proximally and parallel to the femur distally. The gluteus medius and tensor fascia lata were explored, and then the adhesion point of the gluteus medius to the anterior trochanter major was partially separated. After exposure of the capsule, the hip joint was reached with a T-shaped opening. The femoral head was dislocated to the anterior side and osteotomized. The appropriate retractors were placed on the acetabulum, and then reaming was applied to the acetabulum. After implantation of the acetabular cup, the femur was reamed in the figure-of-four position and an appropriate femoral stem was placed. Length and offset were adjusted through trialing, and then the prosthesis was placed according to the press-fit method. After the closure of the layers, a position boot was applied.

In the posterolateral approach, the patient was prepared in the lateral decubitus position on the operating table, and then the fibers of the gluteus maximus muscle were separated in a parallel manner using an approximately $15-\mathrm{cm}$ incision. The short external rotators and capsule were opened. The femoral head was dislocated to the posterior side. the acetabulum was reached after cutting the femoral neck and retracting to the anterior side. The acetabular and femoral components were implanted using the same method as in the anterolateral approach. The external rotators, which were cut, and the remainder of the capsule were sutured in place by opening the bone tunnel. A position boot was applied after the closure of the layers and turning the patient to a supine position.

Clinical evaluation of the patients was made according to the Harris Hip Score (HHS) (18) preoperatively and 4 weeks, 6 weeks, 3,6 , and 12 months postoperatively. Radiological evaluation was made at 6 weeks, 3 and 12 months postoperatively. The inclination and anteversion of the acetabular cup, stem orientation, and component fixation were examined on the radiographs. Heterotopic ossification was evaluated according to the criteria provided by Brooker et al $(19,20)$.

IBM SPSS Statistics Ver. 21.00 (IBM Corp.) and MS-Excel 2013 software was used for all the statistical analyses and calculations. The values obtained from the patients in the study were input into the computer program. The necessary checking for errors and corrections were made. The conformity to the normal distribution of continuous variables (age, length of incision, and so forth) was examined graphically and using the Shapiro-Wilk test. In the presentation of descriptive statistics, continuous data were expressed as mean \pm standard deviation (SD) and categorical data as number (n) and percentage (\%).the chi-square test was applied for comparing categorical variables (HHS, femoral stem orientation) according to the study groups. A P value less than 0.05 was accepted as statistically significant.

\section{RESULTS AND DISCUSSION}

A total of 70 patients were followed up for a mean duration of 25 months (range 12-34 months), 34 in the anterolateral group and 
TABLE 1: Patient demographic and preoperative data.

\begin{tabular}{lll}
\hline Patient demographics & Anterolateral group & Posterolateral group \\
Total & 34 & 36 \\
$\quad$ Male & 22 & 29 \\
$\quad$ Female & 12 & 7 \\
Mean age (year) & $64.3 \pm 10.1$ & $63.8 \pm 9.2$ \\
Mean body mass index $\left(\mathrm{kg} / \mathrm{m}^{2}\right)$ & $29.2 \pm 5.1$ & $28.4 \pm 3.7$ \\
Primary diagnosis & & 25 \\
$\quad$ Primary osteoarthritis & 23 & 5 \\
$\quad$ Secondary osteoarthritis & 5 & 0 \\
$\quad$ Inflammatory osteoarthritis & 2 & 6 \\
$\quad$ Osteonecrosis & 4 & 4.2 \\
Length of stay & 4.56 & 25 \\
\hline
\end{tabular}

36 in the posterolateral group (Table 1). The total hip prosthesis was applied to the right hip in 49 patients (70\%) and to the left hip in 21 (30\%). General anesthesia was applied to all patients. The mean surgical time was determined as $145 \pm 20 \mathrm{~min}$ in the anterolateral group and $132 \pm 12 \mathrm{~min}$ in the posterolateral group, with no statistically significant difference between the groups (Table 2). Total mean blood loss during surgery and postoperatively was measured as $\pm 100 \mathrm{~mL}$ in the anterolateral group and $1050 \pm 100 \mathrm{~mL}$ in the posterolateral group, with no statistically significant difference between the groups.

Superficial wound infection was determined in a total of three patients (4.2\%): two (5.8\%) in the anterolateral group and one (2.7\%) in the posterolateral group (Table 3). These were all successfully treated with wound care and antibiotic

TABLE 2: Surgical and immediate postoperative data.

\begin{tabular}{lcc}
\hline Variable (mean \pm SD) & Anterolateral & Posterolateral \\
\hline Surgical time $(\mathrm{min})$ & $145 \pm 20$ & $132 \pm 12$ \\
İncision $(\mathrm{cm})$ & $15.2 \pm 1.1$ & $14.2 \pm 0.9$ \\
Blood loss $(\mathrm{mL})$ & $1150 \pm 100$ & $1050 \pm 100$ \\
$\begin{array}{l}\text { Acetabular cup inclination } \\
\text { (degree) }\end{array}$ & $44.2 \pm 6.2$ & $45.4 \pm 7.2$ \\
$\begin{array}{l}\text { Acetabular cup anteversion } \\
\text { (degree) }\end{array}$ & $23.1 \pm 5.9$ & $25.8 \pm 8.2$ \\
Stem orientation & & \\
$\quad$ Valgus & & 1 \\
$\quad$ Neutral & 32 & 35 \\
\hline
\end{tabular}

prophylaxis. Dislocation was determined in three (4.2\%) patients: one (2.9\%) in the anterolateral group and 2 (5.5\%) in the posterolateral group. Closed reduction was applied to all these patients, a position boot was applied for 3 weeks, and no additional surgical intervention was made. Heterotopic ossification was determined as Brooker Grade 1-2 in two of three (8.8\%) patients in the anterolateral group and as Grade 3 in one in the posterolateral group; two (5.5\%) were all Grade $1-2$. Ossification of a degree that could restrict movement was not observed in any patient.

Complications developed in seven (20.5\%) patients in the anterolateral group and $6(16.6 \%)$ patients in the posterolateral group. No statistically significant difference was found in the complication rates between anterolateral and posterolateral groups

TABLE 3: Complications.

\begin{tabular}{lcc}
\hline & Anterolateral & Posterolateral \\
\hline Superficial infection & 2 & 1 \\
Dislocation & 1 & 2 \\
Deep vein thrombosis & - & - \\
Heterotopic ossification & 3 & 2 \\
Hematoma & 0 & 1 \\
Wound dehiscence & 1 & 0 \\
Intraoperative fracture & - & - \\
Leg length abnormalities & & - \\
(cm $\uparrow$ ) & - & 6 \\
Total (postoperative) & 7 & \\
\hline
\end{tabular}


$\left(\chi^{2}=3.131 ; P=0.077\right)$. The difference in the rate of complications corresponded to the complications seen at a higher rate in the anterolateral group, but it was not statistically significant.

The preoperative HHS was below 60 in 30 patients (88.2\%) of the anterolateral group and 42 (91.6\%) in the posterolateral group (Table 4). No statistically significant difference was found in the preoperative HHS between the groups $\left(\chi^{2}=0.01 ; P=0.92\right)$. Postoperatively, the HHS was evaluated as $70-79$ and $\geq 80$. According to this evaluation, the HHS was 70-79 in 5 patients (14.7\%) in the anterolateral group and $4(11.1 \%)$ in the posterolateral group. The HHS was 80 or above in 29 patients (87.8\%) in the anterolateral group and 32 (88.8\%) in the posterolateral group. No statistically significant difference was found $n$ the postoperative HHS between the groups i $\left(\chi^{2}=0.083\right.$; $P=0.773)$.

Femoral stem orientation was evaluated in two categories as neutral or malposition (varus-valgus) from the radiological measurement results. The femoral stem was evaluated as neutral in 32 (94.1\%) patients in the anterolateral group and 35 (97.2\%) in the posterolateral group. No statistically significant difference was found in the radiological examination of the femoral stem orientation between the groups $\left(\chi^{2}=0.14 ; P=0.708\right)$.

Debates continue as to which surgical approach is superior in applying total hip prosthesis (21). Several defined approaches have their own advantages and disadvantages.

The anterolateral approach has the advantages of lower rates of dislocation and better exposure of the acetabulum. However, it is necessary to cut the anterior fibers of the gluteus medius, which prevents access to the femur. The inferior branches of the superior gluteal nerve are at risk. All these factors may lead to abductor insufficiency and patient dissatisfaction. In a study by Lindgren et al (22) in Sweden, the anterolateral and posterior approaches were compared in 90,632 patients who underwent cemented THA between 1992 and 2009. The Lubinus SP2 and

TABLE 4: Preoperative and postoperative Harris Hip Score.

\begin{tabular}{lcc} 
& Anterolateral & Posterolateral \\
\hline Preoperative & 30 & 33 \\
60 & 4 & 3 \\
$60-69 \downarrow$ & 5 & \\
Postoperative & 5 & 4 \\
$70-79$ & 29 & 32 \\
$80 \uparrow$ & &
\end{tabular}

Spectron EF type prostheses were applied to the patients. More revisions were required for aseptic loosening, while fewer revision operations were made because of dislocation in the anterolateral group.

The most significant advantage of the posterior approach is that good exposure of the acetabulum and femur can be obtained without touching the abductor. The greatest disadvantage is the risk of dislocation. A study by Zhang et al (23) was reported that repairing the soft tissue using the posterior approach reduced the risk of dislocation and increased HHS. The dislocation rates were compared in a study by Ji et al (24), in which THA patients were treated using a posterior approach or a modified lateral approach. The posterior soft tissue was repaired and no dislocations developed in the patients who were treated using the posterior approach. The other group had three cases of dislocation. Consequently, it was reported that better results of joint stability were obtained with soft tissue repair using the posterior approach compared with the modified lateral approach.

The evaluation of the complications in the two groups showed that superficial infection was seen at a higher rate in the anterolateral group and heterotopic ossification was observed to be at a significantly high level in both the groups. The cause of the infection, which responded to antibiotic treatment in the anterolateral group, was thought to be soft tissue trauma during femoral reaming. Few studies in the literature are related to heterotopic ossification. Morrey et al (25) reported that a lower rate of heterotopic ossification was observed using the posterior approach compared with the anterolateral and transtrochanteric approaches. Supporting that view, Eggli and Woo (26) reported heterotopic ossification at a rate $8.1 \%$ higher using anterior and anterolateral approaches compared with the posterior approach. Similar results were obtained in the present study with heterotopic ossification at a higher rate of $7.2 \%$ in the anterolateral group. Surgical excision was not necessary for any patient because no functional restrictions were observed.

Although high clinical improvement was observed in both the groups following THA compared with the preoperative status, no statistically significant difference was found between the groups. According to a study by Smith et al (27), the surgical approach is a significant factor in patient-reported results. Evaluations using three different scoring systems showed that the results were better in the patients who were treated using the posterior approach. In a study by Palan et al (3), THA patients 
with anterolateral or posterior incision were followed up for 5 years. Although pain and functional results were reported to be better in the posterior group in the short term, no difference was found in the clinical scores, dislocation, or revision surgery in the long term (mean duration 5 years).

\section{CONCLUSIONS}

No statistically significant difference was seen in the clinical and radiological results using the anterolateral and posterolateral approaches for applying THA. The most successful results can be obtained using the technique that the surgeon performs better according to his experience of THA.

\section{REFERENCES}

1. Restrepo C, Parvizi J, Pour AE, et al. Prospective randomized study of two surgical approaches for total hip arthroplasty. J Arthroplasty 2010;25:671.

2. Bremer AK, Kalberer F, Pfirmann CWA, et al. Soft-tissue changes in hip abductor muscles and tendons after total hip replacement. J Bone Joint Surg Br 2011;93-B:886.

3. Palan J, Beard DJ, Murray DW, Andrew JG, Nolan J. Which approach for total hip arthroplasty: anterolateral or posterior? Clin Orthop Relat Res. 2009;467:473-7. doi: 10.1007/s11999008-0560-5. Epub 2008 Oct 22.

4. Watson-Jones R. Fractures of the neck of the femur. Br J Surg 1935; 23:787.

5. Gibson A. Posterior exposure of the hip joint. J Bone Joint Surg $\mathrm{Br}$ 1950;32:183-186.

6. Weber M, Ganz R. Modified Smith-Petersen approach and its possibilities for extension. Orthop Traumatol 2002;10:245-257.

7. Hoppenfeld S, deBoer P. Surgical Exposures in Orthopaedics: The Anatomic Approach. 3rd ed. Philadelphia, PA: Lippincott Williams \& Wilkins, 2003.

8. Muller ME. Total hip prostheses. Clin Orthop Relat Res 1970;72:46-68.

9. Masonis JL, Bourne RB. Surgical approach, abductor function, and total hip arthroplasty dislocation. Clin Orthop Relat Res. 2002;405:46-53.

10. Chimento GF, Pavone V, Sharrock N, et al. Minimally invasive total hip arthroplasty: a prospective randomized study. J Arthroplasty 2005;20:139

11. Dorr LD, Maheshwari AV, Long WT, et al. Early pain relief and function after posterior minimally invasive and conventional total hip arthroplasty. A prospective, randomized, blinded study. J Bone Joint Surg Am 2007;89:1153

12. Sculco TP. Minimally invasive total hip arthroplasty: in the affirmative. J Arthroplasty 2004;19:78.
13. Hartzband MA. Posterolateral minimal incision for total hip replacement: technique and early results. Orthop Clin North Am 2004;35:119.

14. Berger RA. Total hip arthroplasty using the minimally invasive two-incision approach. Clin Orthop Relat Res 2003;(417):23241.

15. Meneghini RM, Smits SA, Swinford MS, et al. A randomized prospective study of three minimally invasive surgical approaches in total hip arthroplasty. J Arthroplasty 2008;23:68.

16. Popischill M, Kranzl A, Mag B, et al. Minimally invasive compared with traditional transgluteal approach for total hip arthroplasty. A comparative Gait analysis. J Bone Joint Surg Am 2010;92:328.

17. Oinuma K, Eingartner $C$, Saito $Y$, et al. Total hip arthroplasty by a minimally invasive, direct anterior approach. Oper Orthop Traumatol 2007;19:310.

18. A. Hakan Eren. Harris Kalça Skoru. Acta Orthop Traumatol Turc 31: 285-288, 1991.

19. Bono VB, MD, McCarthy MD, Tuner RH, MD: Complications in total hip arthroplasty. Orthopaedic Knowledge Update. Hip and Knee Reconstruction, 2nd ed. American Academy of Orthopaedic Surgeons, p 155-168, 1999.

20. Evans GD : Late complication and their management in total hip arthroplasty. The adult hip. Ed. Callaghan JJ, Rosenberg AG, Rubash HE, vol 1, p 1149-1165, Philadelphia, 1998.

21. Singh JA. Epidemiology of knee and hip arthroplasty: a systematic review. Open Orthop J 2011;16;5:80-5. doi: 10.2174/1874325001105010080.

22. Lindgren V, Garellick G, Kärrholm J, Wretenberg P. The type of surgical approach influences the risk of revision in total hip arthroplasty: a study from the Swedish Hip Arthroplasty Register of 90,662 total hipreplacements with 3 different cemented prostheses. Acta Orthop 2012; 83:559-65. doi:10.31 09/17453674.2012.742394. Epub 2012 Nov 1.

23. Zhang D, Chen L, Peng K, Xing F, Wang H, Xiang $Z$. Effectiveness and safety of the posterior approach with soft tissue repair for primary total hip arthroplasty: a metaanalysis. Orthop Traumatol Surg Res 2015;101:39-44. doi: 10.1016/j.otsr.2014.10.015. Epub 2015 Jan 22.

24. Ji HM, Kim KC, Lee YK, Ha YC, Koo KH. Dislocation after total hip arthroplasty: a randomized clinical trial of a posterior approach and a modifie lateral approach. J Arthroplasty 2012;27:378-85. doi:10.1016/j.arth.2011.06.007. Epub 2011 Jul 28.

25. Morrey BF, Adams RA, Cabanela ME. Comparison of heterotopic bone after anterolateral, transtrochanteric, and posterior approaches for total hip arthroplasty. Clin Orthop 1984;188:160-167.

26. Eggli S, Woo A. Risk factors for heterotopic ossification in total hip arthro-plasty. Arch Orthop Trauma Surg 2001;121:531-535.

27. Smith AJ, Wylde V, Berstock JR, Maclean AD, Blom AW. Surgical approach and patient-reported outcomes after total hip replacement. Hip Int 2012;22:355-61. doi: 10.5301/ HIP.2012.9455 